\title{
Maxillofacial Reconstruction with Patient-specific Implants
}

\author{
${ }^{1}$ Vidya Rattan, ${ }^{2}$ Sachin Rai, ${ }^{3}$ Satnam S Jolly, ${ }^{4}$ Vijay K Meena
}

\begin{abstract}
Oral and maxillofacial defects are both aesthetically and functionally challenging for the surgeon. Autogenous bone grafts seldom fulfill the criteria of three-dimensional replication of the lost hard and soft tissues. Medical grade titanium alloy has recently been used to fabricate three dimensional (3D) customized implants for the reconstruction of various upper and midface bony defects. This paper presents three cases of midface reconstruction with the help of customized 3D titanium patient-specific implants.
\end{abstract}

Keywords: Patient Specific Implants, Titanium implants, 3D Printing, Zygomatic reconstruction.

How to cite this article: Rattan V, Rai S, Jolly SS, Meena VK. Maxillofacial Reconstruction with Patient-specific Implants. J Postgrad Med Edu Res 2019;53(1):34-37.

Source of Support: Nil

Conflict of Interest: None

\section{INTRODUCTION}

Oral and maxillofacial defects are both functionally and esthetically debilitating for the patient. The prominent position of the face makes it vulnerable to trauma, and war injuries. Similarly, various benign and malignant pathologies add to the etiology of such defects. Reconstruction of these hard and soft tissue defects is challenging for the surgeon. Different autogenous and alloplastic options are used by the reconstructive surgeons but replicating the details of the lost tissues precisely is seldom achieved. Last decade has seen $3 \mathrm{D}$ correction of these defects with various alloplastic materials like sialastic sheets and blocks, Medpore (PMMA) or PEEK implants. ${ }^{1-3}$ Medical grade titanium alloy has recently been used to fabricate $3 \mathrm{D}$ customized implants for the reconstruction of various upper and

\footnotetext{
${ }^{1}$ Professor, ${ }^{2}$ Additional Professor, ${ }^{3}$ Assistant Professor, ${ }^{4}$ Senior Scientist

1-3Unit of Oral and Maxillofacial Surgery, Oral Health Sciences Centre, Postgraduate Institute of Medical Education and Research, Chandigarh, India

${ }^{4}$ Central Scientific Instrument Organisation, Council of Scientific and Industrial Research, Chandigarh India

Corresponding Author: Sachin Rai, Additional Professor, Unit of Oral and Maxillofacial Surgery, Oral Health Sciences Centre, Postgraduate Institute of Medical Education and Research, Chandigarh, India, Phone: 91 172-275 6831, e-mail: drraisachin@ gmail.com
}

midface bony defects. ${ }^{4,5}$ This paper presents three cases of midface reconstruction with the help of customized 3D titanium alloy.

\section{CASE REPORT}

\section{Case 1}

A 32-year old male reported to the outpatient department with the chief complains of draining sinus from the right infraorbital region (Fig. 1A). He also revealed generalized loosening of maxillary dentition and foul smell from the oral cavity. His CBCT scan revealed the moth-eaten appearance of the right zygoma, maxillary alveolus and palatal bone (Fig. 1B). With a differential diagnosis of osteomyelitis, an incisional biopsy and culture were performed that subsequently revealed mucormycosis. In the

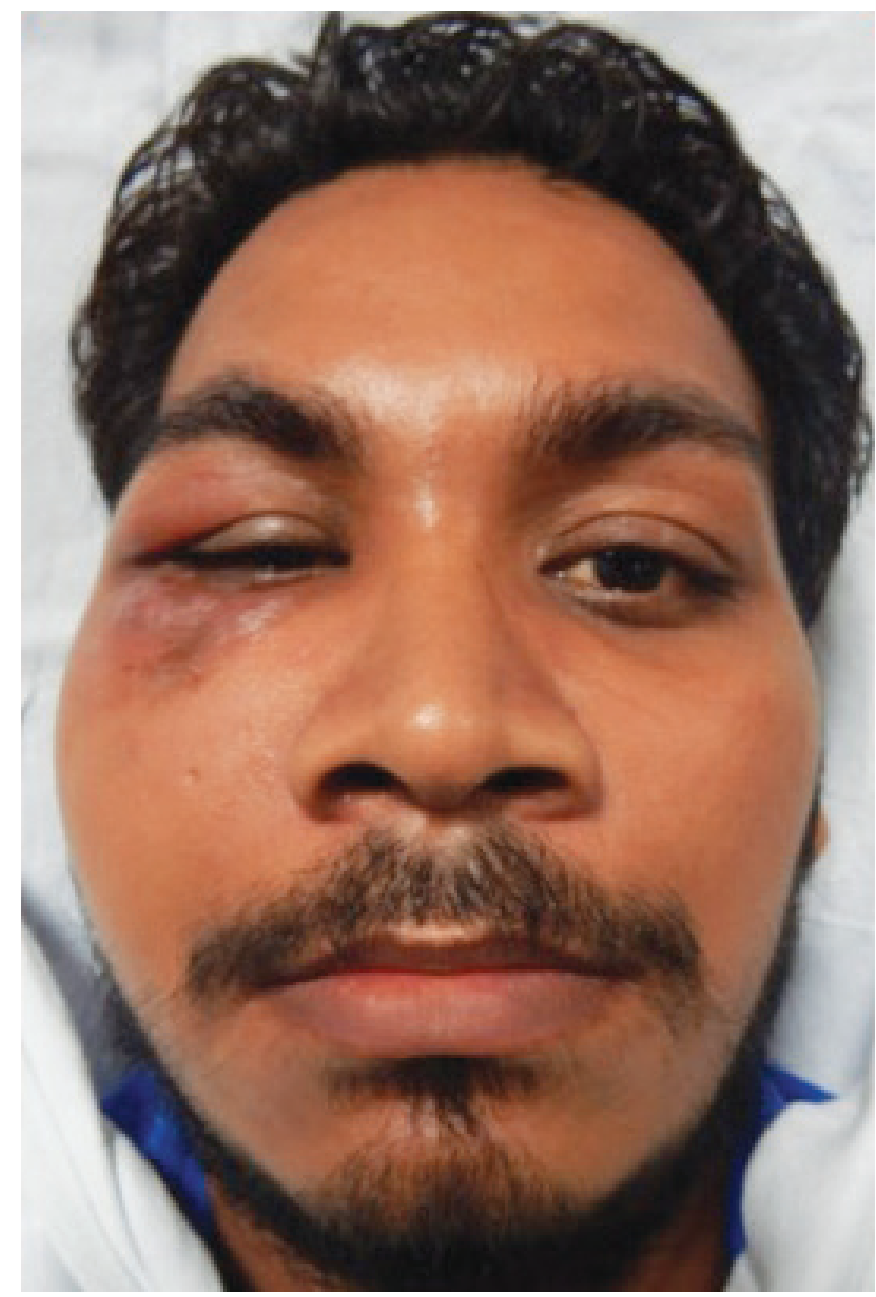

Fig. 1A: Chronic inflammatory swelling in the right infraorbital region with draining sinus 

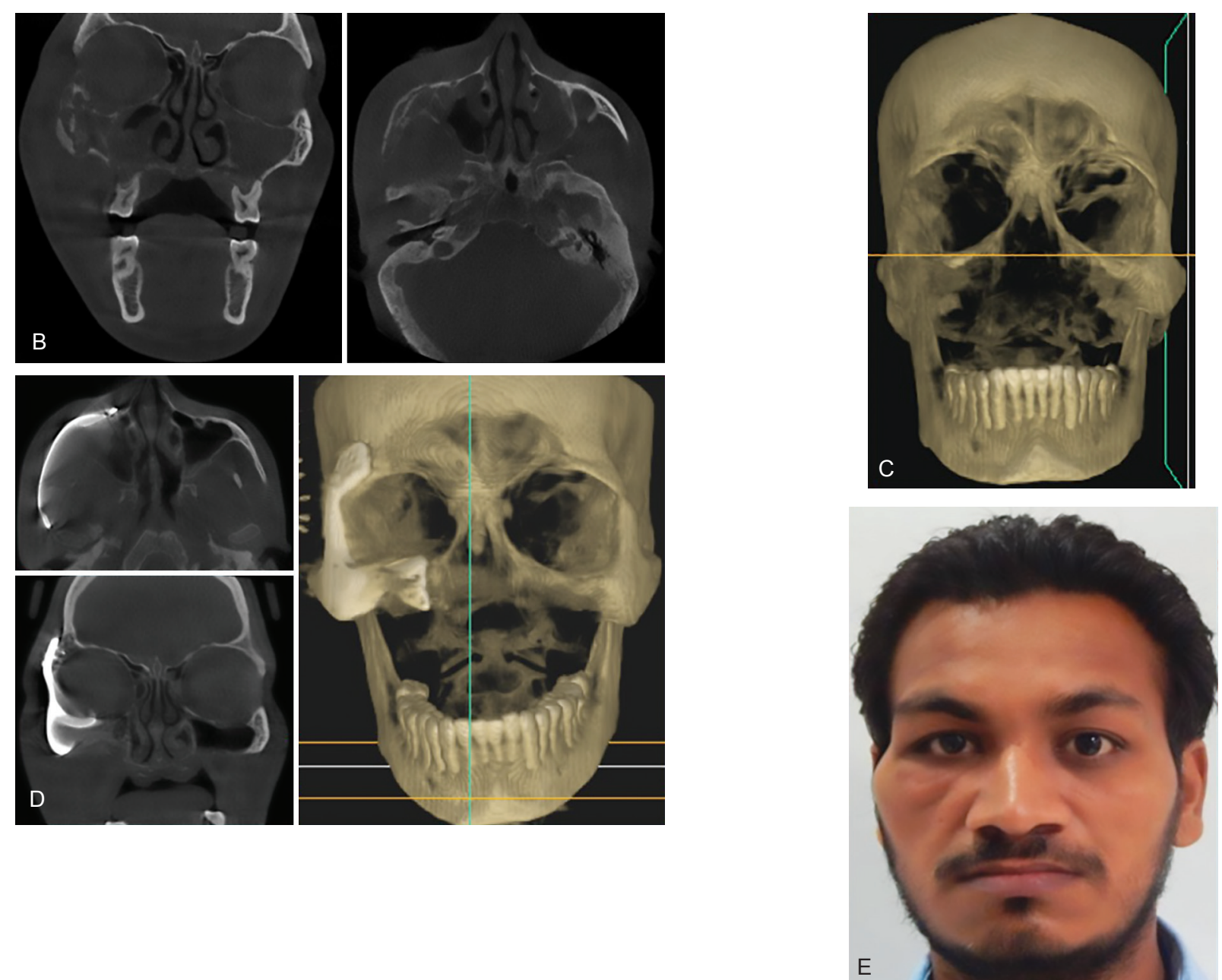

Figs 1B to E: (B) CBCT scan revealing moth-eaten appearance of the right zygomatic and maxillary bone including palate; (C) CBCT scan after the removal of maxillary alveolus and palatal bone.; ( $D$ and $E)$ : Postoperative $C B C T$ scan and clinical picture depicting PSI restoring the contours of the face.

first stage, his necrosed maxillary alveolar bone and palatal bone was removed and sinus lavage was performed under general anesthesia (Fig. 1C). The patient was put on oral posaconazole $200 \mathrm{mg}$ QID for 3 months as the first line of treatment. ${ }^{6} \mathrm{~A}$ titanium 3D customized patient-specific implant was fabricated. This was placed after resection of the involved zygomatic bone. The postoperative outcome has been satisfactory, and the patients have been on regular follow-up for the last three years (Figs 1D and E).

\section{Case 2}

An 18 year old female reported with hard swelling on the left side of the cheek with deep dull bony pain (Fig. 2A). Her scan revealed an intra-osseous neoplasm in the left zygoma having a honeycomb appearance (Fig. 2B). An incisional biopsy revealed a diagnosis of intra-osseous hemangioma. Resection and reconstruction of left zygoma were planned with 3D PSI (Fig. 2C). Her postoperative course has been satisfactory with a regular follow-up of two years (Figs 2D and E).

\section{Case 3}

A 40-year-old male suffered massive craniofacial injuries due to a road traffic accident (Fig. 3A). Because of his head injury component and its sequelae, any surgical intervention in upper and midface was postponed. In a first stage, his fractured maxilla and mandible were fixed. He was recalled after six months for correction of malar flattening and reconstruction of the orbital floor. A twopiece PSI was planned for him to reconstruct his right zygoma and right orbital floor (Fig. 3B). His postoperative phase revealed correction of the malar flattening, ocular dystopia, and enophthalmos (Figs 3C and D).

\section{DISCUSSION}

Patient-specific implants with titanium alloy have revolutionized the reconstructive surgeries and their outcome. It is now been used in orthopedics, neurosurgery and craniomaxillofacial surgery in the developed countries. ${ }^{7}$ Its planning and manufacturing require acquiring data from the CT scan in a dicom file format. This dicom file is converted into an STL file that depicts 

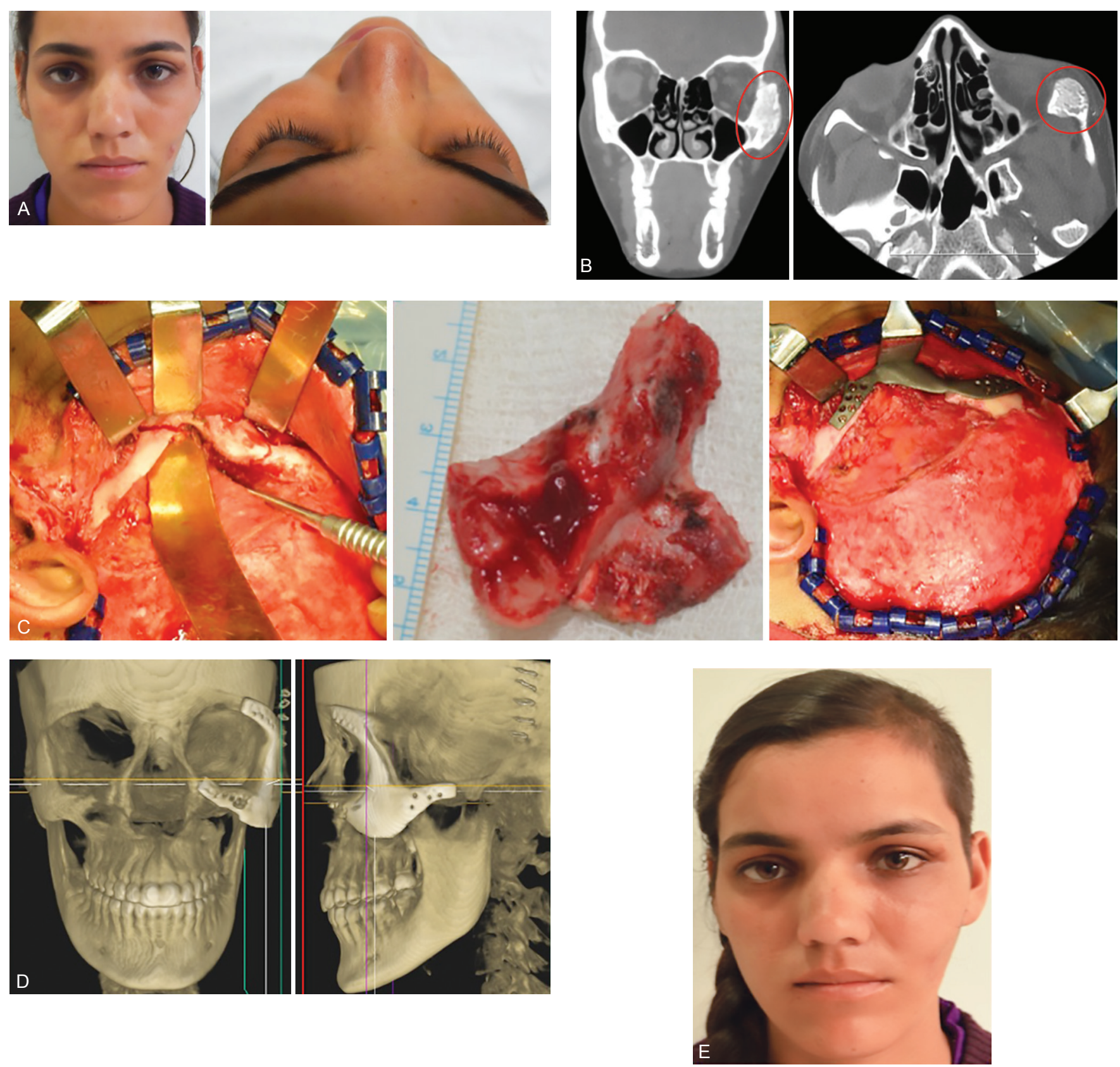

Figs 2A to E: (A) Clinical picture showing swelling in the left cheek region; (B) CT scan depicting honeycomb appearance of the left zygomatic bone; (C) Intraoperative picture of resected zygoma and fixation of PSI; (D) Postoperative 3D CBCT showing restoration of anatomy of the zygomatic complex; (E) Postoperative clinical facial appearance

the dimensions of the implant. This STL file is converted into SLI file format that designs the implants into layered (30 microns approx.) structure. This SLI format file is sent to the 3D printer that builds the implant by the process of additive (layerwise) manufacturing. Once out of the 3D printer, the implant is removed from the platform and its support. It is polished, wiped and sterilized before packaging and delivery. ${ }^{8}$ The surgeon is intricately involved in the designing and approval of the implant.

In the three cases discussed here, it was nearly impossible to reconstruct the three-dimensional architecture of the zygoma with any autogenous bone. Zygoma has a tetrapodal structure and supports the eyeball and gives anteroposterior projection to the face. Its flattening or loss can severely affect the facial esthetics and ophthalmic functions. Most of the time, the patient carries the burden of a distorted face and unesthetic appearance for life. This severely affects his social life. Titanium is a biocompatible, inert material which shows the tendency of osteointegration with the bone. Titanium implants are been used for internal maxillomandibular fixations and as dental implants since last few decades. Its biocompatibility is proven and remains the material of choice for maxillofacial internal fixation. Titanium 3D PSIs hold a promising future for such patients. 

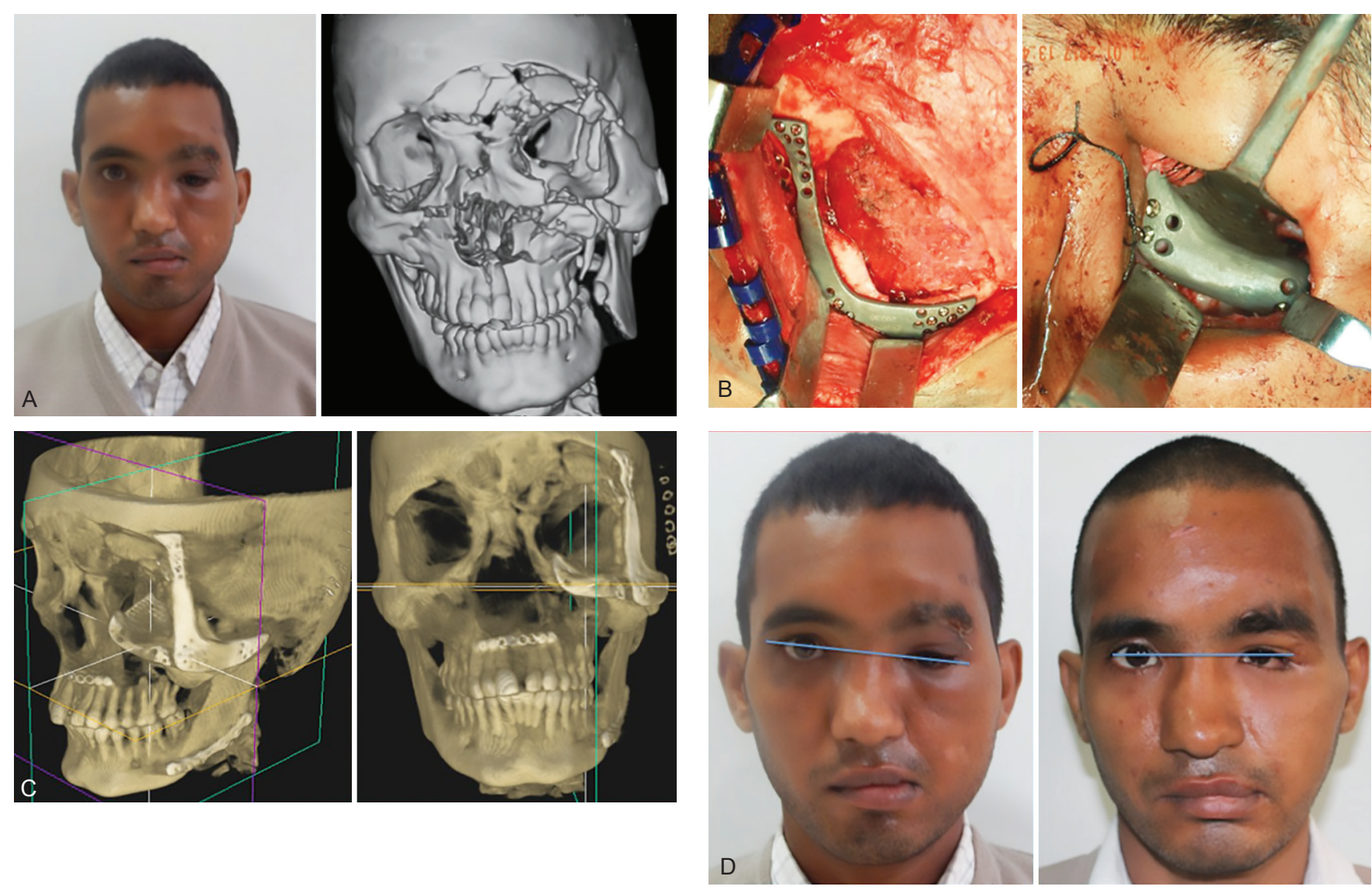

Figs 3A to D: (A) Preoperative clinical and radiological appearance of the patient; (B) Two-piece PSI fixed intra-operatively; (C) Postoperative 3D CBCT showing both PSIs in place; (D) Comparison of pre- and post-operative (1 month) clinical facial appearance

\section{REFERENCES}

1. Guevara-rojas G, Figl M, Schicho K, Seemann R, Traxler H, Vacariu A, et al. Patient-specific polyetheretherketone facial implants in a computer-aided planning workflow. J Oral Maxillofac Surg 2014;72:1801-1812.

2. Hoffmann J, Cornelius CP, Groten M, Probster L, Schwenzer N. Orbital reconstruction with individually copy-milled ceramic implants. British J Oral Maxillofac Surg 1998;35:207-209.

3. Ivy EJ, Lorenc ZP, Aston SJ. Malar augmentation with silicone implants. Plast Recon Surg 1995;96-98.

4. De moraes PH, Olate S, Cantin M, Assis AF, Santos E, Silva FO et al. Anatomical reproducibility through $3 \mathrm{D}$ printing in cranio-maxillo-facial defects. Int J Morph 2015;33:826-830.
5. Gander T, Essig H, Metzler P, Lindhorst D, Dubois L, Rucker $\mathrm{M}$ et al. Patient Specific Implants (PSI) in reconstruction of orbital floor and wall fractures. J Craniomaxillofac Surg 2015;43:126-130.

6. Rai S, Yadav S, Kumar D, Kumar V, Rattan V. Management of rhinomaxillary mucormycosis with Posaconazole in immunocompetent patients. J Oral Bio Craniofac Res 2016;6:55-58.

7. Parthasarathy J. 3D modeling, custom implants and its future perspectives in craniofacial surgery. Anl Maxillofac Surg 2014;4:9-18.

8. Rotaru H, Schumacher R, Kim SG, Dinu C. Selective laser melted titanium implants: a new technique for the reconstruction of extensive zygomatic complex defects. Maxillofac Plast Recon Surg 2015;37:1-4. 